\title{
Functionality and durability of anti - graffiti - systems on concrete
}

\author{
Sandra Jäntsch ${ }^{1,2, *}$, Claudia von Laar ${ }^{2}$, and Henning Bombeck ${ }^{1}$ \\ ${ }^{1}$ University of Rostock, Agricultural and Environmental Sciences, Justus-von-Liebig-Weg 6, 18059 \\ Rostock, Germany \\ ${ }^{2}$ Hochschule Wismar University of Applied Sciences Technology, Business and Design, Faculty of \\ Engineering, Philipp-Müller-Straße 14, 23966 Wismar, Germany
}

\begin{abstract}
Property damage and vandalism through illegal graffiti can be found worldwide. As graffiti increased, so did the interest in proper removal and the possibilities of a high-quality protection system. Antigraffiti systems (AGS) can be used to protect objects and buildings from damage caused by graffiti. At present, AGS is still recommended for use in unspecified areas for plastics, metal, wood, brick, concrete and natural stone. In practice, it has turned out that no AGS is suitable for all surfaces. A specific reference to surface quality and properties is missing. For graffiti protection, however, the surface properties are of particular importance. They influence the liability of the AGS on the one hand and the removability of the graffiti on the other. This study is intended to demonstrate the extent to which concrete types and surfaces influence the functionality and durability of permanent AGS. This paper presents first results of practical tests on 180 concrete test specimens after currently one year of outdoor weathering. The results from three years of weathering are to be used to conclude the study for the development of an evaluation concept. Matching surfaces and AGS, with focus on the surface properties should be defined.
\end{abstract}

\section{Introduction}

Colorful and fancy graffiti on facades and buildings can be legal works of art, but more often they appear in the form of unsightly scribbles that distort the urban landscape. The cost of removing illegal graffiti and graffiti scribblings is enormous. The annual expenditure for the removal of graffiti in the USA amounts to about 15 billion US dollars. In Europe, the situation is similar, for example, the Barcelona authorities spend around 4 million euros a year on the fight against graffiti [1]. The annual costs of illegal graffiti in Germany amount to around 200 million euros [2]. London is record holder, with expenditures of about 160 million dollars [1]. The problem of graffiti in public space is undisputedly one of the most current topics that modern metropolises have to deal with. Figure 1 shows illegal graffiti scribbles on residential buildings in Berlin, Prenzlauer Berg

\footnotetext{
*Corresponding author: sandra.jaentsch@uni-rostock.de / sandra.jaentsch@hs-wismar.de
} 
[3], and Figure 2 shows an illegal work of art, probably created by the artist Banksy, on a wall in Fitzrovia in central London [4].

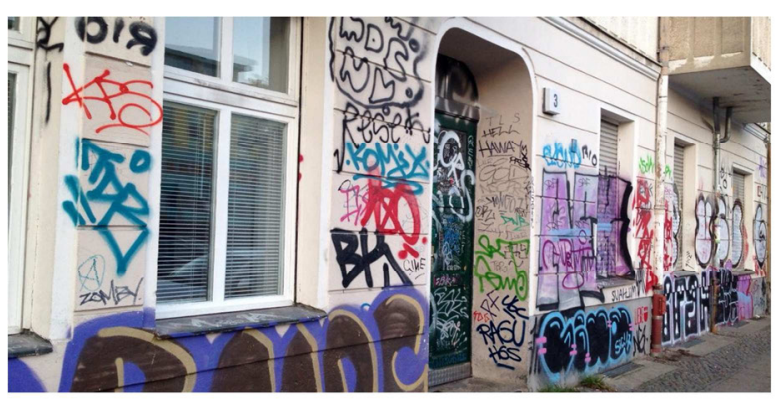

Fig. 1. House wall in Berlin [3]

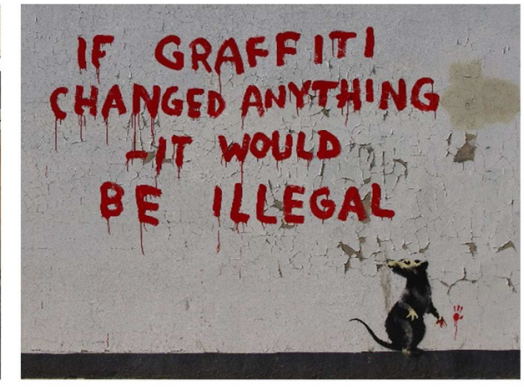

Fig. 2. Wall in London [4]

Examples of Krakow, the second largest city in Poland, are shown below. As early as 2013, the Working Group to Combat Illegal Graffiti in Krakow decided to successfully protect the public space from vandalism, but at the same time good graffiti should be promoted as an art form by specifically marking public spaces and legally releasing them for graffiti art [5]. In Kraków, more and more restaurants and shops are turning to artists to beautify their buildings, protecting themselves from unwanted graffiti and graffiti scribbles.

As part of the local project "100 murals for Krakow", the currently typical street art at the town house in Kazimierz was created in 2016 (see Figure 3) [6]. Figure 4 shows perhaps the most famous mural in Krakow by the artist Blu [7]. The brick wall in Figure 5 surrounds a school, extends over an entire city block and is considered the birthplace of Krakow street art [8].

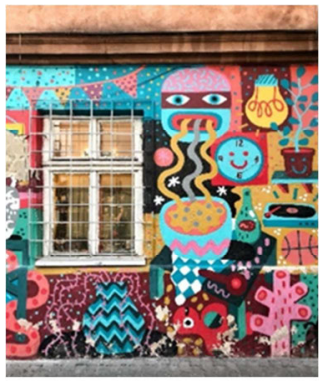

Fig. 3. Street art [9]

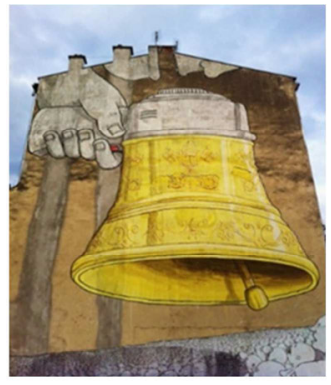

Fig. 4. Blu-graffiti [10]

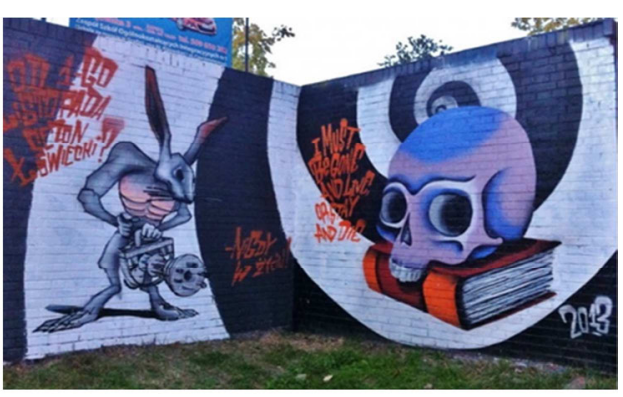

Fig. 5. Wall school Aleja Kijowska 8 [11]

In addition to the sometimes legal and tolerated illegal graffiti (street art), Poland also has to deal with numerous graffiti scribbles. Every year around two thousand unwanted inscriptions and graffiti appear on Krakow's walls [12]. These include politically motivated graffiti, gang signs and insults [13]. Estimates from 2015 assume annual damage of 6 million zlotys (around 1.32 million euros) in Krakow [14].

There are various ways to counter vandalism through illegal graffiti. Anti-graffiti systems (AGS) offer an effective and durable option. The focus here should be on the simple and quick removal of graffiti and graffiti scribblings without damaging the surface.

Within the scope of this study, the fundamentals are developed to what extent functionality and durability of permanent anti-graffiti systems are influenced by the concrete quality and the concrete surface on outdoor components. In the technical data sheets of the manufacturers for AGS, the areas of application are listed unspecific and equally recommended for plastics, metal, wood, bricks to concrete and natural stone, and a specific reference to the surface quality is missing. For graffiti protection, surface 
properties are particularly important, since they influence the adhesion of graffiti protection systems on the one hand and the removability of graffiti on the other [15]. So far, functionality and durability have been assessed primarily on the basis of the AGS system. The surface to be protected played a subordinate role or was not sufficiently specifically included in the assessment. A more precise recording and examination of the building material surface with regard to a later coating or impregnation by AGS has not been carried out so far.

In this work the interaction of selected concrete surfaces and selected anti-graffiti systems is examined for durability and functionality. In the long-term test (outdoor weathering) over a period of 3 years, selected visual and physical parameters and properties are determined and evaluated in regular cycles. After completing the test series, a test and evaluation concept is to be developed. The different surface qualities, surface designs and concrete qualities should play an important role. So far, research results on the possible dependencies of the surface properties and the resulting adhesion properties have been lacking. A new perspective between the interaction of the permanent AGS on different concrete surfaces should serve to develop the evaluation system and thus enable and simplify the correct application of the materials.

\section{Materials}

This study is intended to demonstrate the extent to which different types of concrete and surfaces of concrete influence the functionality and durability of permanent AGS. For this purpose, the surface quality of normal, high-strength and fiber-reinforced concrete test specimens is examined. A total of 180 concrete samples were tested, including 6 different concrete test specimens (U1 - U6), which differ in the type, quality and surface treatment of the concrete. The concrete samples are defined and shown in Table 1 below.

Table 1. Concrete test specimen

\begin{tabular}{|c|c|c|c|c|c|}
\hline U1 & U2 & U3 & U4 & U5 & U6 \\
\hline & & & & & \\
\hline $\begin{array}{c}\text { Facade panel } \\
\text { high-strength } \\
\text { concrete } \\
\text { Formwork } \\
\text { smooth }\end{array}$ & $\begin{array}{c}\text { Facade panel } \\
\text { high-strength } \\
\text { concrete } \\
\text { honed } \\
\text { surface }\end{array}$ & $\begin{array}{c}\text { Facade panel } \\
\text { high-strength } \\
\text { concrete } \\
\text { blasted } \\
\text { surface }\end{array}$ & $\begin{array}{c}\text { Concrete } \\
\text { angles } \\
\text { fiber } \\
\text { reinforced } \\
\text { Exposed } \\
\text { concrete }\end{array}$ & $\begin{array}{c}\text { Walkway } \\
\text { slab } \\
\text { Standard } \\
\text { concrete }\end{array}$ & $\begin{array}{c}\text { Formwork } \\
\text { concrete slab } \\
\text { Standard } \\
\text { concrete } \\
\text { Board } \\
\text { formwork }\end{array}$ \\
\hline
\end{tabular}

The concrete samples were provided by various manufacturers. The dimensions of the samples U5 are $10 \mathrm{~cm} \times 25 \mathrm{~cm}$ (Width x Height), all other samples have a size of $15 \mathrm{~cm} \mathrm{x}$ $20 \mathrm{~cm} .30$ test specimens are used for each surface of the test series. Identical AGS were applied to all concrete substrates to be coated. Four different systems were used, which were applied according to the manufacturer's instructions. For the cleaning process, cleaning agents and cleaning agents that are connected to the AGS and recommended by the manufacturer are used. Table 2 lists and characterizes the anti-graffiti systems (AGS) and their cleaning agents $(\mathrm{R})$. 
Table 2. Anti-graffiti systems and related cleaners

\begin{tabular}{|c|c|l|l|}
\hline System & Designation & \multicolumn{1}{|c|}{ Product } & \multicolumn{1}{c|}{ Characteristic / Basis } \\
\hline \multirow{2}{*}{$\begin{array}{c}\text { System } \\
1\end{array}$} & AGS 1 & $\begin{array}{l}\text { Hydrophobing and } \\
\text { graffiti protection } \\
\text { (facade cream) }\end{array}$ & $\begin{array}{l}\text { Silane, siloxane, fluoroacrylate } \\
\text { copolymers (C2 to C6) }\end{array}$ \\
\cline { 2 - 4 } & R1 & Gel cleaner & Surfactant-solvent mixture \\
\hline $\begin{array}{c}\text { System } \\
2\end{array}$ & AGS 2 & $\begin{array}{l}\text { Graffiti impregnation } \\
\text { (watery dispersion) }\end{array}$ & Fluoropolymers, water \\
\cline { 2 - 4 } & R2 & Gel cleaner & Surfactant-solvent mixture \\
\hline $\begin{array}{c}\text { System } \\
3\end{array}$ & AGS 3 & $\begin{array}{l}\text { Graffiti protective } \\
\text { varnish }\end{array}$ & $\begin{array}{l}\text { water-based 2-component polyurethane- } \\
\text { polymer combination }\end{array}$ \\
\cline { 2 - 4 } & R3 & Liquid cleaner & Surfactant-solvent mixture \\
\hline \multirow{2}{*}{$\begin{array}{c}\text { System } \\
4\end{array}$} & AGS 4 & $\begin{array}{l}\text { Graffiti protective } \\
\text { varnish }\end{array}$ & $\begin{array}{l}\text { water-based 2-component polyurethane } \\
\text { varnish, silicone and wax-free }\end{array}$ \\
\cline { 2 - 4 } & R4 & $\begin{array}{l}\text { Liquid cleaner (spray } \\
\text { application) }\end{array}$ & Surfactant-solvent mixture \\
\hline
\end{tabular}

Uncoated as well as coated samples from each surface are exposed to a paint application in regular cycles and cleaned after 24 hours. For this study, five paint orders are used per cycle. These are always four sprays (graffiti-, car -, other sprays) and a permanent marker, which correspond to the current spectrum. Figure 6 shows the colours used in the first cycle. Concrete plates sprayed with paint before first cleaning are shown in Figures 7 and 8.

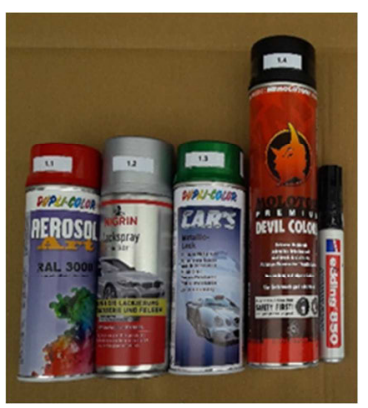

Fig. 6. Colorant

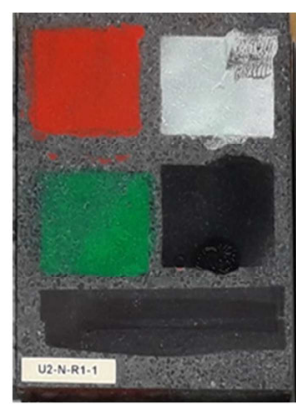

Fig. 7. Close-up of a sprayed sample U2

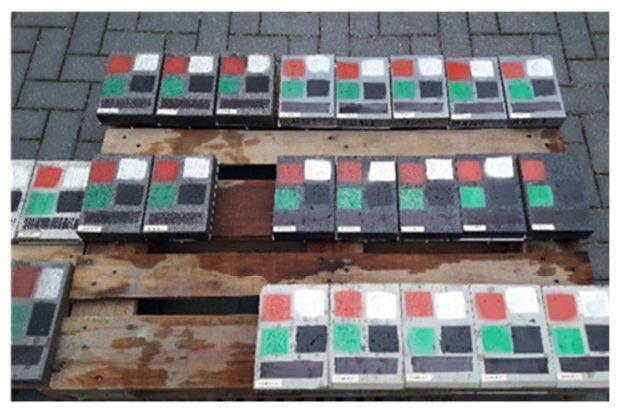

Fig. 8. Samples with colorant before cleaning

\section{Experimental procedure}

The specimens are tested for various parameters in the untreated state, after application by the AGS, during and after the outdoor weathering and after cleaning. The tests take place at regular intervals. A cycle consists of outdoor weathering, paint application and cleaning and extends over a period of four months. Table 3 provides a clear overview of selected parameters and associated methods. 
Table 3. Selection of parameters and associated methods

\begin{tabular}{|c|l|l|}
\hline Number & \multicolumn{1}{|c|}{ Parameter } & \multicolumn{1}{c|}{ Method / Device } \\
\hline 1 & Surface impairment & visual \\
\hline 2 & Gloss measurements & Reflectometer - glossmeter \\
\hline 3 & Brightness measurements & Chroma Meter CR-400 \\
\hline 4 & Water absorption coefficient & $\begin{array}{l}\text { Immersion process according to DIN EN ISO } \\
15148\end{array}$ \\
\hline 5 & Contact angle & Contact angle measurements device OCA-20 \\
\hline 6 & Roughness measurements & 3D laser microscopy \\
\hline
\end{tabular}

The functionality includes the changes in gloss and brightness of the substrate and the AGS. The color change of the base body due to the application of the AGS and the color change of the samples due to the weather are measured. The colorant removal is assessed visually, be aid of a reference plate [16]. The functionality of the AGS strongly depends on the type of substrate and the surface properties. The determination of the water absorption coefficient, the wetting angle as well as the roughness are in the focus for a precise assessment of the durability. These parameters are important and necessary for the development of processes for the visualization or quantification of signs of aging of the anti-graffiti layers. In the following, the gloss measurements and roughness as important influencing factors for functionality and durability are explained and evaluated more precisely.

Shine is the subjective, visually perceived property of a surface that reflect incident light in a certain way. A glossy impression is not a physical property and therefore cannot be measured directly. In addition to an objectively measured reflection value (gloss value), personal perception always plays an important role when assessing a surface. However, human language offers only a few terms for classifying a gloss, such as high-gloss, glossy, semi-matt or matt (dull) [17].

The gloss measurements on the test specimens are carried out in accordance with DIN EN ISO 2813 [18] with a reflectometer mounted on the test specimen surface (gloss meter), with a set measuring geometry of $85^{\circ}$. The measurements are carried out on both AGStreated and untreated test specimens. Five measured values are determined in each case and the mean value is calculated from this. The gloss values indicate the possible optical changes of the building material surface due to the application of an AGS, from the climatic load as well as after cleaning. Figure 9 shows a gloss meter on a concrete test specimen; the gloss value has no unit and is specified in GU (gloss unit) in accordance with DIN EN ISO 2813 [18]. Figure 10 illustrates how differently an AGS "shines" on the respective concrete substrate.

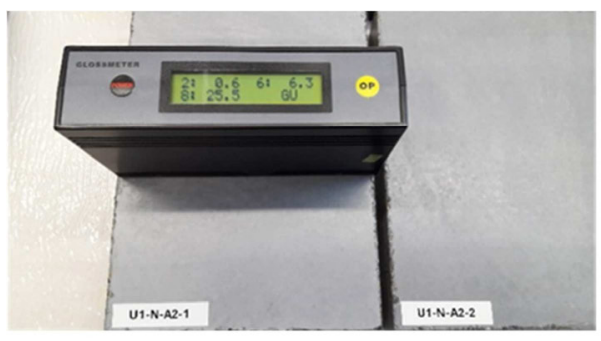

Fig. 9. Measurement with the glossmeter

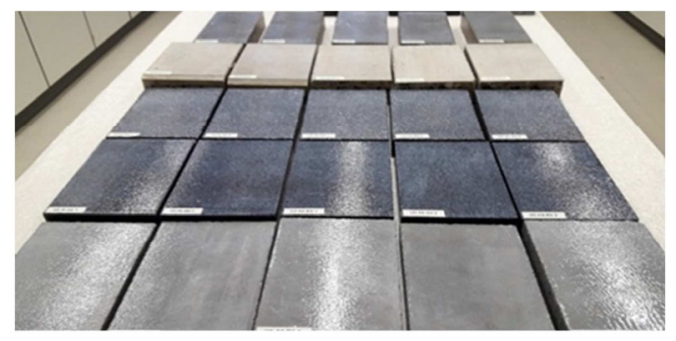

Fig. 10. Surface gloss on the samples

The gloss value is assessed according to DIN EN 1062-1:2004-08 [19] as listed in the following table 4 . 
Table 4. Gloss value according to DIN EN 1062-1

\begin{tabular}{|c|l|c|c|}
\hline \multicolumn{2}{|c|}{ Category } & Measuring angle & Requirement \\
\hline G1 & glossy & $60^{\circ}$ & $>60$ \\
\hline \multirow{2}{*}{ G2 } & \multirow{2}{*}{ medium gloss } & $60^{\circ}$ & $\leq 60$ \\
\cline { 3 - 4 } & & $85^{\circ}$ & $>10$ \\
\hline \multirow{2}{*}{ G3 } & matt & $85^{\circ}$ & $\leq 10$ \\
\hline
\end{tabular}

The structure and roughness of the concrete surfaces are examined and evaluated with the help of a 3D laser scan microscope system VK 9700 from Keyence on the uncoated and coated samples and also in regular cycles. The surface is significantly evaluated by the roughness value. However, the surface roughness measurement cannot be defined as clearly as is the case, for example, with longitudinal measures. For this reason, there are different measuring methods for the quality of the surface, which can be found, for example, under the abbreviations Rt (maximum roughness depth), Ra (middle roughness value), Rp (medium smoothing depth) and Rz (roughness depth). The lowest "valley" (peak height) and the highest "mountain" (peak depth) of a measuring section are recorded for the determination of Rz. The height difference of the peaks (the delta) corresponds to the ratio Rz1 to Rz5. The arithmetic mean is then taken from several individual measuring ranges Rzi. The mean corresponds to the average roughness depth Rz. Normally, the averaging takes place over 5 individual measuring distances (see Figure 11). The average roughness depth $\mathrm{Rz}$ is always given in $\mu \mathrm{m}$ [20]. Figures 12 and 13 show the measurements with the 3D laser scanning microscope.

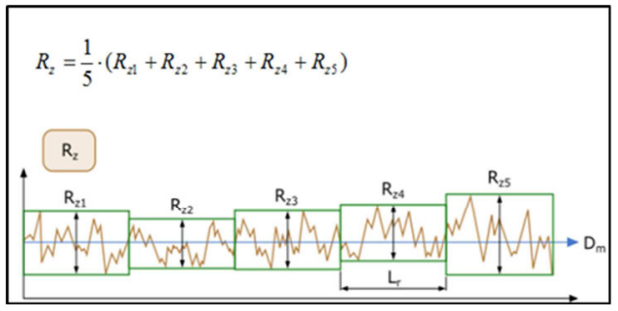

Fig. 11. Roughness: formula and graphics [21]

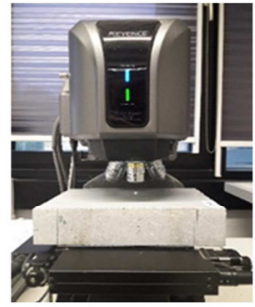

Fig. 12.3D laser scanning microscope

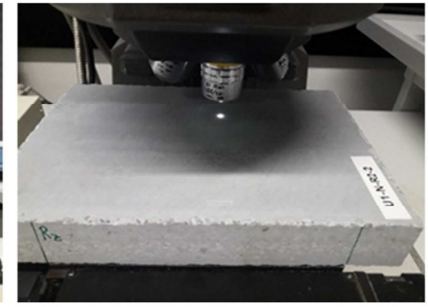

Fig. 13. Measurement of roughness on a sample from the U1 series

\section{Test results}

\subsection{Results of measurements for gloss}

This study can already show initial findings from three outdoor weathering and cleaning cycles, which were carried out over a period of one year.

The results of the gloss measurements are summarized in Figure 14 by aid of 6 bar charts. Average values were formed from all individual measurements, compared and evaluated. Each chart is calculated to an underground and contains the evaluated data of the first year. All mean values of the zero samples without coating and cleaning (NP), zero sample without AGS but with cleaning (R), sample with AGS (AGS) and all samples coated with AGS and cleaned (AGS+R) can be read off. 


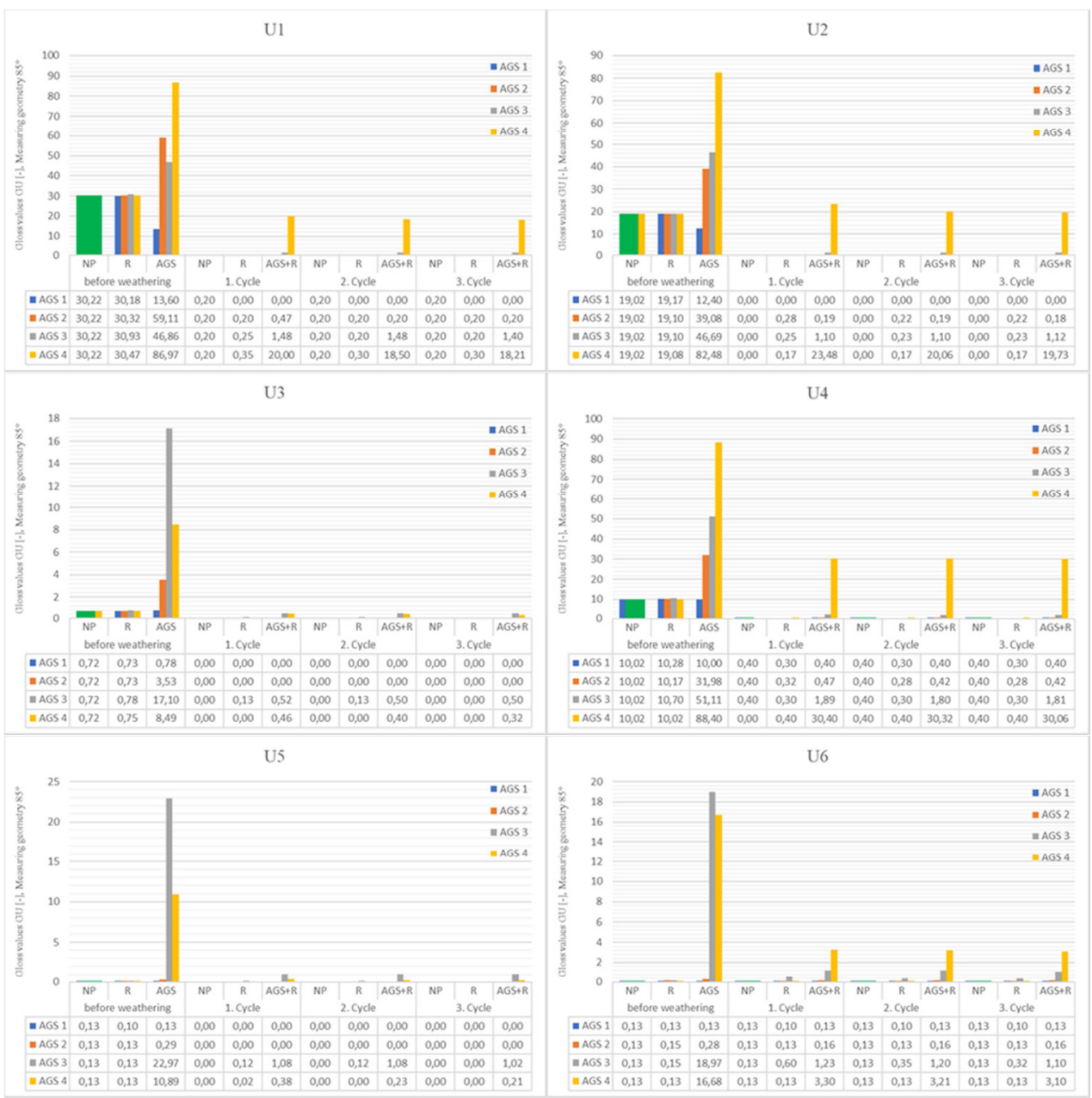

Fig. 14. Changes in the gloss of the concrete surfaces U1 to U6

The zero samples are according to DIN EN 1062-1: 2004-08 [19] as follows: The samples of the substrates U1 and U2 are with a GU of 30 or $19>10$ and therefore have a certain gloss. The specimens of substrates U3 to U6 are matt, their GU values are all $\leq 10$.

The gloss changes differently due to the application of the systems used. AGS 1 is largely unchanged, only the samples U1 and U2 lose about half of their gloss, but with a GU of 13.6 and 12.4 still the classification of the medium gloss. The AGS 2 increases the existing surface gloss on all samples. With the exception of samples U4, however, everyone can maintain their original gloss level. The samples U4 are now classified with a medium gloss. The AGS 3 increases the gloss values for all substrates to such an extent that they correspond to the medium gloss and can even be classified as glossy due to an increase of up to 170 times. The increased values are clearly visible. The situation is similar with the AGS 4, only the substrate U3 has retained its gloss rate, with all other surfaces the gloss was significantly increased, sometimes by a factor of 330 . System 4 can also be regarded as glossy, sometimes even very glossy.

Due to the influence of the weather, all samples lose a lot of shine. After one year of outdoor exposure, the values of the reference samples for all surfaces are between 0.0 and 0.40 and can be assigned to the matt classification with $\leq 10$. The uncoated samples $(\mathrm{R})$ change in their gloss development identical to the zero samples (NP) during outdoor 
weathering and cleaning. The coated samples (AGS $+\mathrm{R})$ also lose their shine due to outdoor weathering and additional cleaning in the first year. AGS 1 and 2 with values between 0.0 and 0.40 are in the range of the zero samples, no differences can be seen optically here. The test specimens coated with AGS 3 and 4 also show a loss of gloss. The gloss values of the AGS 3 are nevertheless up to 8 times higher than the values of the blank samples, but again correspond to the classification matt. However, the system is visually noticeable. The AGS 4 constantly maintains the highest gloss values, while the samples U3, U5 and U6 are again in the matt range, but the values are up to 100 times higher than the zero samples. This system is also clearly visually perceptible and still looks slightly shiny.

\subsection{Results for measurements of roughness}

The results of the roughness measurements are summarized in Figures 15 - 17. Here, too, arithmetic mean values were formed from all individual measurements.

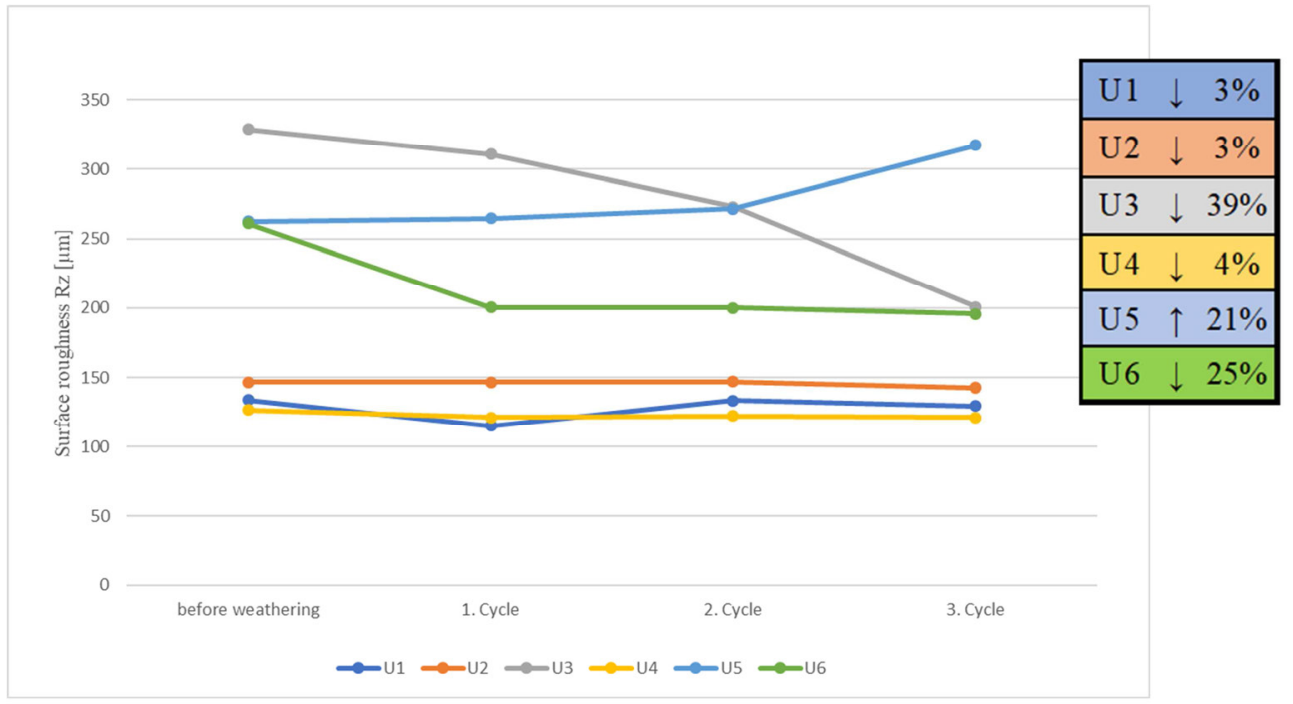

Fig. 15. Modification of the roughness of the zero samples (NP) U1-U6 under outdoor weathering

Regular surface roughness tests show that the zero samples (NP) are constantly influenced after one year of outdoor weathering. The surface-smooth concrete test specimens U1, U2 and U4 remain stable. In contrast, the sample with a machined or rough surface change significantly. As can be seen in Figure 15, the surface profile of the blasted facade panel U3 is significantly reduced by the weathering. The roughness decreases by $39 \%$, which can be explained by dirt deposits on the roughened surface. The blasted surface offers good adhesion for fine dirt particles. Such dirt adhesion is not to be expected on the very smooth surfaces. The concrete test specimens U6 also experience a decrease in roughness as a result of outdoor weathering, which decreases by about $25 \%$. Due to the production with slab formwork, the formwork skin was treated with cement paste in order to achieve a separation layer between the formwork and concrete. This cement pastes still clearly adhered to the samples and could therefore influence the roughness. The proportion decreases with the weather and is rinsed off by rainwater, which leads to a reduction in roughness. The roughness of the standard concrete walkway slab U5 increases by $21 \%$ under the influence of the weather. This can be attributed to the concrete composition. In contrast to high-strength concretes, this is a standard concrete that can be stronger 
influenced by the weather (rain, sun, frost) on the surface. The pores become larger and the roughness increases steadily.

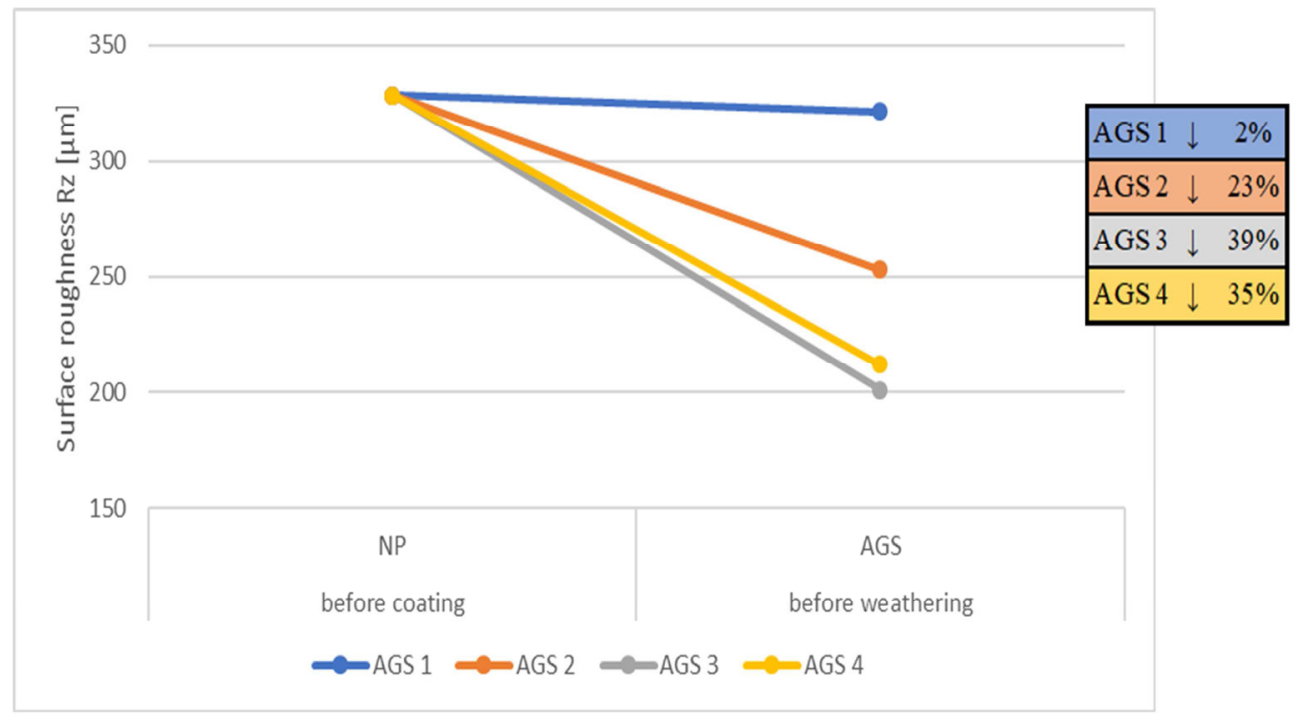

Fig. 16. Changing the roughness of the U3 sample series with the AGS coating

All surfaces of the samples coated with AGS lost roughness due to the coating. Figure 16 shows an example of the changes to the sample series U3, the blasted facade panels. The samples U3 with the AGS 1 lost only slightly roughness, 2\%. The surface roughness of all samples of the U3 series is significantly influenced by AGS 2, 3 and 4, here the roughness is reduced by up to $39 \%$. By cleaning the samples coated with AGS 1, 2 and 4, the roughness changes only slightly within one year, they remain stable. AGS 3 represents a special case, which is shown in Figure 17.

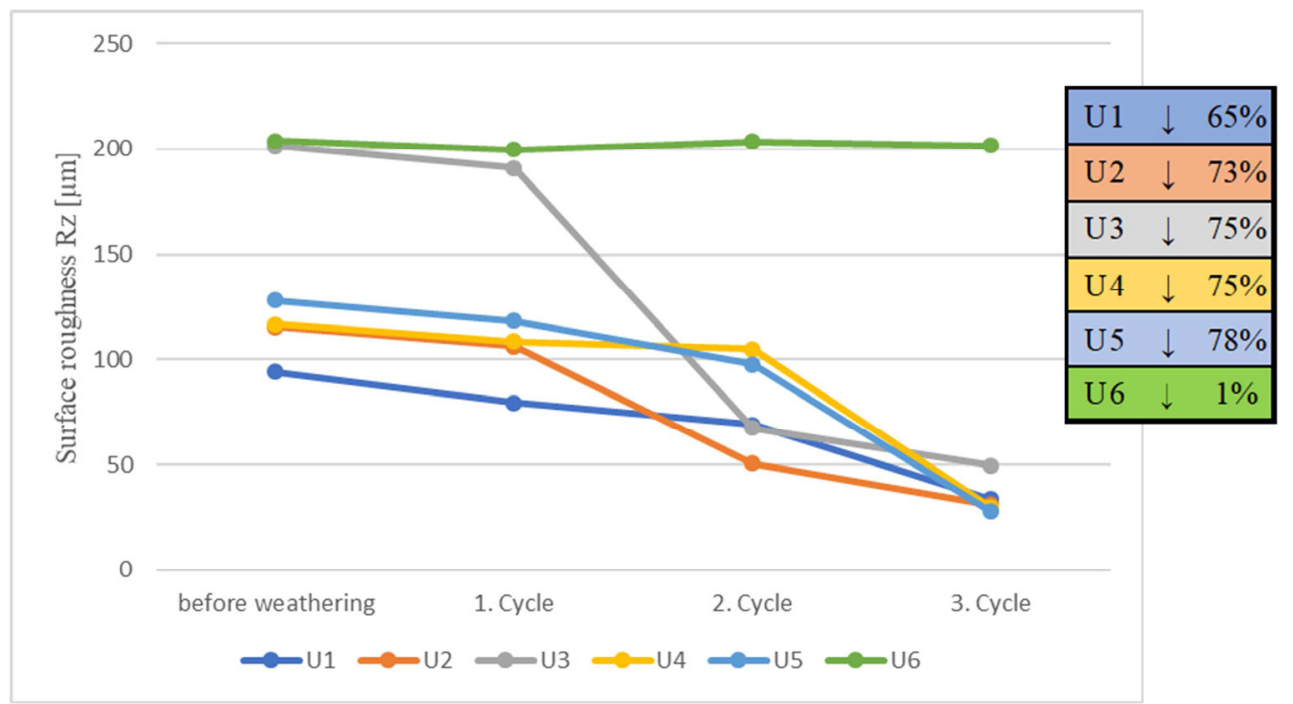

Fig. 17. Modification of the roughness of all samples of series U1 to U6 coated with AGS 3 - with outdoor weathering 
With the exception of AGS 3, the roughness changes only slightly within one year if the coated samples are cleaned. Systems 1, 2 and 4 remain stable. AGS 3 represents a special case, which is shown in Figure 18. After one year of weathering and cleaning, the roughness of samples U1 to U5 drops again by over $65 \%$, partially around $78 \%$, and the coated surface becomes even smoother. The only exception is the panel formwork sample U6, which, as already has been described, is influenced by the cement paste. The significant change in the surface roughness of the samples U1 to U5 suggests that AGS 3 strongly influences the concrete surface.

\section{Conclusions}

Already after one year of outdoor weathering, including 3 cleaning cycles, first conclusions can be drawn from the results. As already explained in detail, no concrete surface and no anti-graffiti system can be regarded as representative of all materials on the market.

The results so far from the demonstrated gloss and roughness measurements show how differently the surfaces can act as an independent material, as well as in connection with an AGS. Not only the AGS influences the surface, but also the surface itself. Smooth and very smooth surfaces can and must be considered differently than surfaces that have been treated superficially or have been produced in a rougher version during manufacture.

For proper application, it is necessary to consider and evaluate the surface to be protected in advance. Before an object or facade is provided with an AGS, the change in appearance that the respective AGS and outdoor weathering can cause should be considered.

The investigations have shown that the evaluation according to DIN EN 1062-1: 200408 [19] is too imprecise for the gloss value and can lead to different visual impressions within a class. The results of AGS 3 show that this system changes the visual gloss perception of smooth or polished surfaces particularly strongly. Here a gloss level of matt or medium gloss can also be perceived as highly glossy. The anti-graffiti systems 3 and 4, with a higher degree of gloss, are much easier to clean. Since the roughness of these systems has decreased the most due to the coating from AGS, a connection can be assumed here. Because in the previous cleaning cycles it became clear that the surfaces with less roughness are easier to clean. The blasted, the form worked and the surface of the walkway slab are increasingly difficult to clean, more and more colorants remain on the surface or the AGS.

Outdoor Weathering itself has an impact on the surface and should not be neglected. As the changes in the roughness of the uncoated reference samples have shown, weathering has a particular impact on the rough test specimens. The surfaces U3, U5 and U6 have lost roughness due to weathering alone. On the other hand, the smooth and ground facade panels U1 and U2 and the angle support in exposed concrete U3 look provided stable values.

In order to enable the evaluation of the systems in interaction with the subsurface more clearly, further parameters must be included and evaluated in the assessment. Further outdoor weathering and cleaning cycles in the next two years should allow an even more precise assessment. An evaluation concept should be created and the functionality and durability should be defined more precisely. 


\section{References}

1. http://www.rynekfarb.pl/koszty-usuwania-graffiti-na-swiecie/ (2020)

2. https://www.gea.de/leser/zms_artikel,-kunst-oder-schmiererei-_arid,552640.html (2020)

3. https://www.prenzlauerberg-nachrichten.de/2018/02/06/graffiti-hochburg-prenzlauerberg/ (2020)

4. https://news.fitzrovia.org.uk/2011/04/25/banksy-graffiti-fitzrovia/ (2020)

5. http://krakow.pl/krakau_weltoffene_stadt/mehr/37044,741,komunikat,graffiti_im_offe ntlichen_raum.html (2020)

6. https://www.inyourpocket.com/krakow/corner-of-ul-nowa-ul-jozefa_152622v (2020)

7. https://www.inyourpocket.com/krakow/ding-dong-dumb_120341v (2020)

8. https://www.inyourpocket.com/krakow/Corner-of-ul-Najowki-and-alKijowska_121965v (2020)

9. https://www.inyourpocket.com/krakow/Krakow-Street-Art_73712f\#\&gid=1\&pid=1 (2020)

10. https://s.inyourpocket.com/gallery/69468.jpg (2020)

11. https://www.inyourpocket.com/krakow/Corner-of-ul-Najowki-and-alKijowska_121965v\#\&gid=1\&pid=6 (2020)

12. https://wiadomosci.onet.pl/krakow/krakow-w-koncu-pozbedzie-sie-graffiti-ruszaeksperyment/yrkw1yq (2020)

13. https://www.inyourpocket.com/krakow/Krakow-Street-Art_73712f (2020)

14. http://www.krakowpost.com/11363/2016/02/krakow-local-news-monday-8-february2016 (2020)

15. https://www.jpost.com/diaspora/swastika-and-other-graffiti-painted-on-wall-of-formerkrakow-ghetto-603455 (2020)

16. https://www.picuki.com/tag/wislasharks (2020)

17. L. Goretzki: Graffiti-Schutzsysteme für Fassadenbaustoffe 3, (1998)

18. TP-AGS-Beton TL/TP-ING Teil 3 Abschnitt 2 (2012)

19. http://docplayer.org/110804198-Messung-der-gerichteten-reflexion-anoberflaechen.html (2020)

20. DIN EN ISO 2813:2015-02 (2014)

21. DIN EN 1062-1:2004-08 (2004)

22. https://www.precifast.de/oberflaechenrauheit-oberflaechenangabe-zeichnungen/ (2020)

23. http://www.technisches-zeichnen.net/technisches-zeichnen/diverses/rauheitswerte.php (2020) 